\title{
Biopsy from Recurrent Lesion May Change Further Treatment Plan in Metastatic Breast Cancer
}

\author{
Kadri Altundag $^{1}$ (D)
}

Received: 7 March 2017 /Revised: 9 March 2017 / Accepted: 17 March 2017 /Published online: 3 April 2017

(C) Korean Society of Nuclear Medicine 2017

Dear Editor,

I wish to congratulate Park and colleagues on the case report [1] in which they presented an unusual case of Horner's syndrome in recurrent breast cancer. In the case presentation part, I would like to draw attention to the detailed information about the hormonal status of breast cancer at the time of diagnosis and at recurrence. Although the authors did not mention it, hormonal receptors are positive at the time of diagnosis and become negative when the breast cancer recurs. Discordance of hormone and HER-2 receptors has been reported in a series of studies. Receptor status has been reported to change in both directions, yet alteration occurs mostly in the loss of positivity for both receptors, as happened in the current case. A number of mechanisms may be responsible. The factors suggested include: tumor heterogeneity, clonal selection of tumor cell subpopulations, genetic instability of tumor cells, local or systemic treatments, the time that elapses between primary tumor and metastasis, receptor status determination techniques, and the site of metastasis [2]. In the light of current data, for treatment plans that target the receptors, a biopsy specimen from the metastatis of breast cancer must also be evaluated for al- terations in receptor status. In the current study, a biopsy of recurrent breast tumor tissue supported this proposal that the patient did not receive hormonal therapy since hormone receptors were negative and instead combination chemotherapy showed good response with improved ptosis.

\section{Compliance with Ethical Standards}

Conflict of Interest Kadri Altundag declares that he has no conflict of interest.

Ethical Approval For this type of study formal consent is not required.

\section{References}

1. Park S, Kim TS, Kim SK. Unusual Horner's syndrome in recurrent breast cancer: evaluation using (18)F-FDG PET/CT. Nucl Med Mol Imaging. 2017;51:93-6. doi:10.1007/s13139-016-0437-6.

2. Arslan C, Sari E, Aksoy S, Altundag K. Variation in hormone receptor and HER-2 status between primary and metastatic breast cancer: review of the literature. Expert Opin Ther Targets. 2011;15:21-30.
Kadri Altundag

altundag66@yahoo.com

1 MKA Breast Cancer Clinic, Tepe Prime,

Cankaya 06800 Ankara, Turkey 